\title{
Cloning and Expression in Pichia pastoris of a New Cytochrome P450 Gene from a Dandruff-causing Malassezia globosa
}

\author{
Eun Chang Lee', Seul Ong Ohk ${ }^{1}$, Bo Young Suh', Nahee Park', Beom Joon Kim², \\ Donghak $\mathrm{Kim}^{3}$ and Young-Jin Chun ${ }^{1}$ \\ ${ }^{1}$ College of Pharmacy, \\ ${ }^{2}$ Department of Dermatology, College of Medicine, Chung-Ang University, Seoul 156-756 \\ ${ }^{3}$ Department of Biological Sciences, Konkuk University, Seoul 143-701, Korea
}

(Received February 19, 2010; Revised February 24, 2010; Accepted February 26, 2010)

\begin{abstract}
The Malassezia fungi are responsible for various human skin disorders including dandruff and seborrheic dermatitis. Of the Malassezia fungi, Malassezia globosa (M. globosa) is one of the most common in human scalp. The completed genome sequence of M. globosa contains four putative cytochrome P450 genes. To determine the roles of Malassezia P450 enzymes in the biosynthesis of ergosterol, we isolated MGL3996 gene from M. globosa chromosomal DNA by PCR. The MGL3996 gene encodes an enzyme of 616 amino acids, which shows strong similarity with known CYP52s of other species. MGL3996 gene was cloned and expressed in Pichia pastoris (P. pastoris) heterologous yeast expression system. Using the yeast microsomes expressing MGL3996 protein, a typical P450 CO-difference spectrum was shown with absorption maximum at $448 \mathrm{~nm}$. SDS-PAGE analysis revealed a protein band of apparent molecular weight $69 \mathrm{kDa}$ and Western blot with anti-histidine tag antibody showed that MGL3996 was successfully expressed in P. pastoris. Cloning and expression of a new P450 gene is an important step to study the P450 monooxygenase system of $M$. globosa and to understand the role of P450 enzymes in pathophysiology of dandruff.
\end{abstract}

Key words: CYP52, Dandruff, Malassezia fungi, P450, Pichia pastoris

\section{INTRODUCTION}

Malassezia species has been known as major pathogenic yeasts that associate with the common skin disorders including dandruff, pityriasis versicolor, seborrheic dermatitis, psoriasis, and atopic dermatitis in human (Guillot et al., 2008; Zisova, 2009; Cafarchia and Otranto, 2008). So far, the genus Malassezia has been shown to comprise at least 13 species based on ribosomal DNA characterization and their ability to grow in certain media: $M$. furfur, M. sympodialis, M. slooffiae, M. obtusa, $M$. globosa, $M$. restricta, $M$. pachydermatis, M. yamatoensis, M. nana, M. japonica, $M$. equine, M. caprae, and M. dermatis (Guého et al., 1996; Mayser et al., 1997; Morishita et al., 2006; Sugita et al., 2005).

Of these Malassezia species, M. globosa and M. restricta are the most commonly isolated species from the skin of dandruff patients (Gemmer et al., 2002). Despite their asso-

Correspondence to: Young-Jin Chun, College of Pharmacy, ChungAng University, 221 Huksuk-dong, Dongjak-gu, Seoul 156-756, Korea E-mail:yjchun@cau.ac.kr ciation with multiple skin disorders, little is known about these yeasts. Recently, total genomic studies of Malassezia globosa CBS 7966 were completed and the $8.9 \mathrm{Mb}$ genome, secretory proteome, and expression of selected genes were described (Xu et al., 2007).

Cytochrome P450 (P450, CYP) enzymes are a superfamily of heme-containing monooxygenases involved in the oxidative metabolism of wide range of endogenous and xenobiotic chemicals. P450s also play important roles in the biosynthesis of antibiotics and other biologically active molecules in bacteria, fungi and plants as well as in animals (Nelson et al., 1996). Although the information about P450 enzymes in Malassezia species are completely unknown, the role of P450 in the biosynthetic pathway of fungal steroid may be quite crucial for survival of Malassezia fungi because azole antifungal agents such as ketoconazole are often used for treating dandruff. The main target enzyme of azole antifungal agent is known as CYP51, sterol 14a-demethylase in fungi. Exposure of fungi to azole antifungal agents causes depletion of ergosterol and accumulation of $14 \alpha$ methylated sterols (Koltin and Hitchcock, 1997; Sheehan et al., 1999). This activity of azoles interferes with the func- 
tions of ergosterol in fungal membranes and disrupts the structure of the membrane and other functions (Georgopapadakou and Walsh, 1996) and causes inhibition of fungal growth. Thus, the studies on Malassezia P450s are required to understand Malassezia biology and to develop specialized anti-dandruff agents.

The genome project of the M. globosa CBS 7966 has provided valuable genetic information about Malassezia P450s. Protein sequence similarity analysis using BLAST showed that four probable cytochrome $\mathrm{P} 450$ genes exist in M. globosa. However, their endogenous roles and contribution to Malassezia biology remain completely unknown. In the present studies, we describe the cloning and expression in Pichia pastoris of the M. globosa MGL3996 gene, a new P450 gene encoding a putative protein highly homologous to the CYP52, which is known as n-alkane and fatty acid hydroxylase (Ohkuma et al., 1995; Scheller et al., 1996).

\section{MATERIALS AND METHODS}

Materials. Restriction enzymes and T4 DNA ligase were purchased from TaKaRa Bio (Otsu, Shiga, Japan). Zeocin and yeast nitrogen base was purchased from Invitrogen (Carlsbad, CA, USA). Antibody against His-tag was purchased from Cell Signaling Technology (Danvers, MA, USA). HRP-conjugated mouse secondary antibody was from Santa Cruz Biotechnology (Santa Cruz, CA, USA). Other chemicals were of the highest grade commercially available.

Cell culture. M. globosa strain was purchased from the American Type Culture Collection (ATCC, Manassas, VA). For broth culture, inocula were prepared by the culture of M. globosa on modified Dixon's agar for five to seven days. Then, the colonies were transferred on modified LeemingNotman medium containing $0.1 \%$ glucose, $0.1 \%$ peptone, $0.8 \%$ bile salts, $0.2 \%$ yeast extract, $0.1 \%$ glycerol, $0.5 \%$ Tween $60,3 \%$ olive oil, and $50 \mu \mathrm{g} / \mathrm{m} l$ chloramphenicol (Riciputo et al., 1996). The growth of yeast at $32^{\circ} \mathrm{C}$ was monitored at $530 \mathrm{~nm}$, every $24 \mathrm{~h}$ for five days.

Construction of P450 expression plasmid. M. globosa genomic DNA was extracted using the QIAamp DNA Mini kit (Qiagen). The gene encoding MGL3996 was amplified by PCR from $M$. globosa genomic DNA by using two gene-specific primers (forward primer MGL3996: 5'CGGTTCGAAATGGCAGCATCCGCGTTCATC-3'， initial codon underlined, $S f u$ I site italicized; reverse primer MGL3996: 5'-CGGTCTAGAAAGCTTCTAGTGATGGTGATGGTGATGTTAGTTCAATGGCGTCAT-3', stop codon underlined, $X b a \mathrm{I}$ site italicized, nucleotide sequence encoding six histidine residue bolded). PCR reaction was carried out with genomic DNA as a template, $0.2 \mathrm{mM}$ dNTPs, 1 pmole of each primer, $1.25 \mathrm{mM} \mathrm{MgCl}_{2}, 10 \times$ polymerase buffer, and $2.5 \mathrm{U}$ of Taq DNA polymerase in a total volume of $50 \mu \mathrm{l}$.
The reaction mixture was preheated to $95^{\circ} \mathrm{C}$ for $10 \mathrm{~min}$ and then subjected to 25 cycles of $95^{\circ} \mathrm{C}$ for $1 \mathrm{~min}, 62^{\circ} \mathrm{C}$ for $1 \mathrm{~min}$, and $72^{\circ} \mathrm{C}$ for $2 \mathrm{~min}$; followed by one final cycle of $72^{\circ} \mathrm{C}$ for $10 \mathrm{~min}$. PCR products were analyzed by $1 \%$ agarose gel electrophoresis. PCR products were double digested with $S f u \mathrm{I}$ and $X b a \mathrm{I}$, purified, and then, ligated into the restriction sites of the Pichia pastoris expression vector pPICZ $\alpha A$ (Invitrogen). E. coli DH5 $\alpha$ was transformed with the expression vector and the positive clones were selected on LB agar plates containing ampicillin. Recombinant plasmid was isolated and analyzed by DNA sequencing.

Expression of $\mathbf{P 4 5 0}$ in P. pastoris. YPD growth medium containing yeast extract (1\%), peptone $(2 \%)$ and glucose $(2 \%)$ was inoculated with single colonies of $P$. pastoris $(200 \mathrm{ml})$. The cells were cultured at $29^{\circ} \mathrm{C}$ for $36 \mathrm{~h}$. The cells were then collected by centrifugation for $10 \mathrm{~min}$ at $3000 \times \mathrm{g}$, $4^{\circ} \mathrm{C}$ and resuspended to an approximate $\mathrm{OD}_{600}$ of 2 in $300 \mathrm{ml}$ of BMM medium (1\% yeast extract, $2 \%$ peptone, $100 \mathrm{mM}$ potassium phosphate, $\mathrm{pH} 6.0,1.34 \%$ yeast nitrogen base, and $400 \mathrm{ng} / \mathrm{m} l$ biotin) supplemented with $0.5 \mu \mathrm{M}$ $\delta$-aminolevulinic acid, trace element $(250 \mu \mathrm{l} /$ liter $)$ and zeo$\operatorname{cin}(100 \mathrm{ng} / \mathrm{ml})$. Cells were grown at $29^{\circ} \mathrm{C}$ while shaking at $200 \mathrm{rpm}$ and induced for $96 \mathrm{~h}$ by adding methanol $(0.5 \%)$ every $24 \mathrm{~h}$. After $96 \mathrm{~h}$, the cells were harvested by centrifugation at $3000 \times \mathrm{g}$ for $10 \mathrm{~min} 4^{\circ} \mathrm{C}$. Cells were resuspended in breaking buffer $(50 \mathrm{mM}$ sodium phosphate, $\mathrm{pH} 7.4$, $1 \mathrm{mM}$ EDTA, 5\% (v/v) glycerol, $2 \mathrm{mM}$ DTT, and $1 \mathrm{mM}$ protease inhibitor). The cell suspension was mixed with an equal volume of acid washed glass beads $(0.5 \sim 0.75 \mathrm{~mm}$ in diameter) and disrupted by vortexing $\left(830 \mathrm{~s}\right.$ at $4^{\circ} \mathrm{C}$ with cooling on ice for $30 \mathrm{~s}$ between the cycles). The lysate was separated from cell debris and glass beads by centrifugation at $12,000 \times \mathrm{g}$ for $10 \mathrm{~min}$ at $4^{\circ} \mathrm{C}$. The supernatant was centrifuged at $100,000 \times \mathrm{g}$ at $4^{\circ} \mathrm{C}$ for $1 \mathrm{~h}$ and then the microsomal pellet was resuspended in breaking buffer and stored at $-80^{\circ} \mathrm{C}$.

Quantification of cytochrome P450 content. Protein concentrations were estimated using the bicinchoninic acid method according to the supplier's recommendations (Pierce Chemical Co., Rockford, IL, USA) using bovine serum albumin as a standard. Cytochrome P450 concentration in the isolated membranes was determined by the spectral method of Omura and Sato (1964). The membranes were diluted with sodium phosphate buffer $(0.1 \mathrm{M}, \mathrm{pH} 7.4)$ containing glycerol $(10 \%)$ and triton X-100 $(0.5 \%, \mathrm{v} / \mathrm{v})$. After adding small pieces of sodium dithionite crystals, a reference spectrum was recorded from 400 to $500 \mathrm{~nm}$ using UV1650PC UV/Visible spectrophotometer (Shimadzu, Japan). The solution was then saturated with carbon monoxide for $60 \mathrm{~s}$ and the spectrum was measured again. The cytochrome P450 concentration was calculated from the difference in absorbance between $450 \mathrm{~nm}$ and $500 \mathrm{~nm}$ with an extinction 
coefficient of $91 \mathrm{mM}^{-1} \mathrm{~cm}^{-1}$.

SDS-PAGE and western blot. Extracted proteins were separated by sodium dodecyl sulfate-polyacrylamide gel electrophoresis (SDS-PAGE) on 10\% polyacrylamide gels. Electrophoresis was performed at $40 \mathrm{~mA}$ and $100 \mathrm{~V}$. After finishing electrophoresis, SDS-PAGE gel was stained with Coomassie Brilliant Blue solution $(0.1 \% \mathrm{w} / \mathrm{v})$. For Western blot, gel was electrophoretically transferred onto polyvinylidene difluoride (PVDF) membrane. Membranes were blocked in $5 \%(\mathrm{w} / \mathrm{v})$ nonfat dried milk in Tris-buffered saline with $0.1 \%$ tween 20 (TBST) for $1 \mathrm{~h}$ at $4^{\circ} \mathrm{C}$. Membranes were then incubated for overnight with anti-his-tag antibody at a $1: 1000$ dilution in TBST. Membrane was incubated with a horseradish peroxidase (HRP)-conjugated goat anti-mouse IgG antibody. Proteins were visualized by an enhanced chemiluminescence method using ChemiDoc XRS (Bio-Rad, CA, USA).

\section{RESULTS AND DISCUSSION}

Malassezia fungi have been considered as a major cause of dandruff (Faergemann, 1997). Azole antifungal agents such as ketoconazole, itraconazole, fluconazole, or voriconazole have been leading agents used to treat fungal infections of plants, animals, and human. Azole antifungal agents are also valuable for treating dandruff and seborrheic dermatitis. Because P450 enzymes play an important role in fungal ergosterol biosynthesis and CYP51 is considered as a major drug target for azole antifungal agent, we were interested in P450s in Malassezia species including M. globosa.

Protein sequence similarity analysis using BLAST showed that four probable $\mathrm{P} 450$ genes are existed in M. globosa genome. Identification of probable $\mathrm{P} 450$ genes within a genome is facilitated by the presence of consensus sequences within the amino acid sequences that are known to be present in all P450 proteins. Amino acid sequences such as EXXR in the K-helix and the cysteine residue which forms a fifth axial ligand to the heme iron are important for P450 function and conserved throughout the P450 superfamily (Table 1). A glycine residue, four amino acids upstream of the conserved cysteine in heme binding motif and a threo-

Table 1. Consensus P450 amino acid sequences in Malassezia globosa. Residue conserved in the I-helix (Thr), the K-helix (Glu and Arg), and the heme-binding site (Gly and Cys) are highlighted in bold

\begin{tabular}{cccc}
\hline \hline Gene name & I-helix & K-helix & Heme binding motif \\
\hline MGL2415 & ${ }^{303}$ AGQHT $^{307}$ & ${ }^{365}$ ETLR $^{368}$ & ${ }^{471}$ FGAGRHRCIG $^{480}$ \\
MGL3996 & ${ }^{383}$ AGHET T $^{387}$ & ${ }^{455}$ ESVR $^{458}$ & ${ }^{548}$ FLSGPRSCVG $^{557}$ \\
MGL0310 & ${ }^{332}$ ASQDA $^{336}$ & ${ }^{391}$ ESLR $^{394}$ & ${ }^{467}$ FGSGPHNCIG $^{476}$ \\
MGL1059 & ${ }^{261}$ AGHET $^{265}$ & ${ }^{333}$ ECLR $^{336}$ & ${ }^{415}$ FLMGPRACIG $^{424}$ \\
\hline
\end{tabular}

nine residue in the I-helix known to be involved in oxygen activation were also highly conserved. All of four probable P450s have these conserved amino acid sequences characteristics of P450 enzyme.

Nucleotide and amino acid sequence of the MGL3996 were obtained from NCBI database (XM_001728777) and also were confirmed by DNA sequencing of cloned gene from M. globosa genomic DNA by PCR (Fig. 1). The MGL3996 gene has 1851 nucleotides and encodes a protein of 616 amino acids which is highly homologous to the CYP52s from other yeast species. Amino acid sequence alignment of MGL3996 with Candida albicans CYP52A1, Candida tropicalis CYP52A8, Pichia stipitis CYP52A3 and

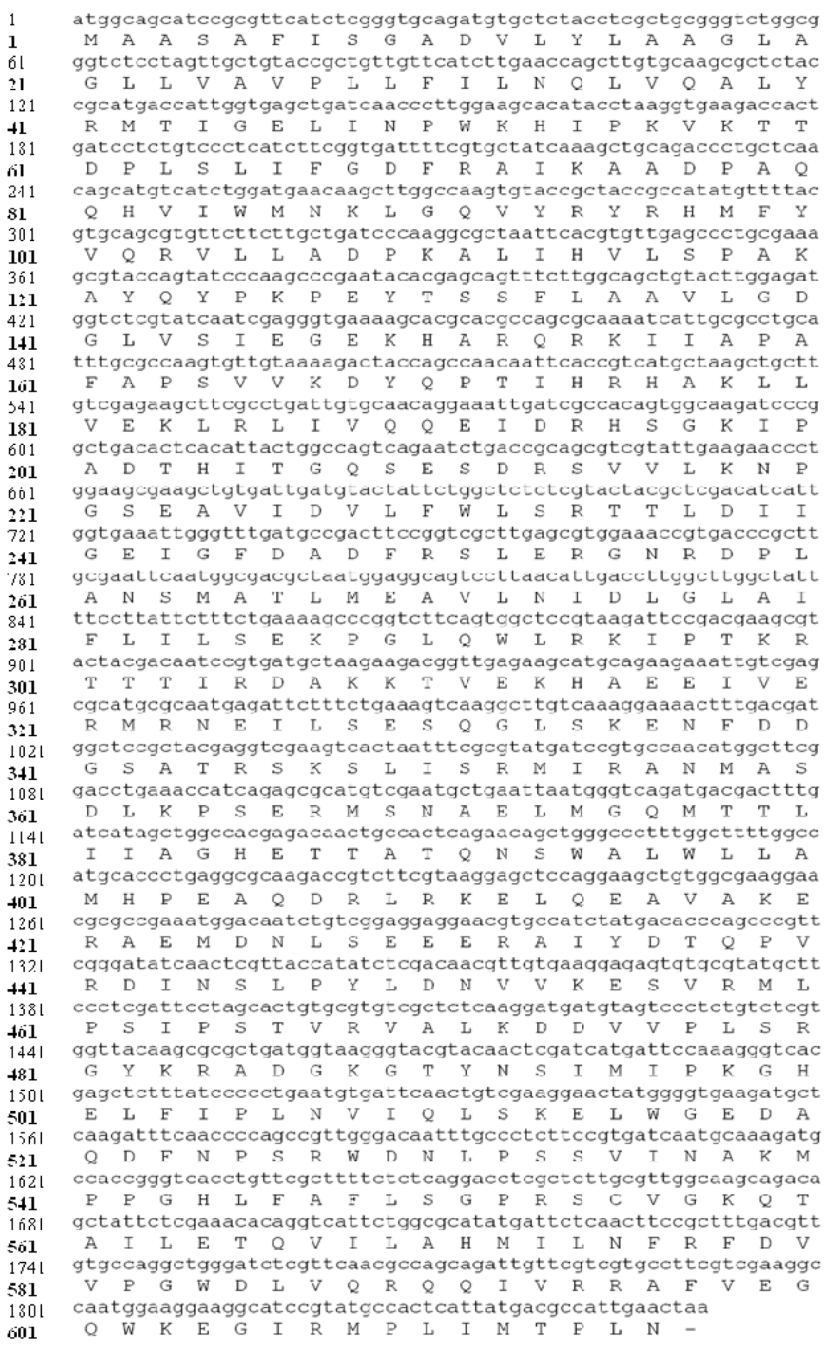

Fig. 1. Nucleotide sequence of Malassezia MGL3996 gene and the predicted amino acid sequence. Nucleotide sequence of MGL3996 were obtained from NCBI database (XM_001728777) and was confirmed by nucleotide sequencing of PCR-cloned gene from $M$. globosa genomic DNA. Nucleotide numbering and amino acid numbering are shown at thin and bold, respectively. 

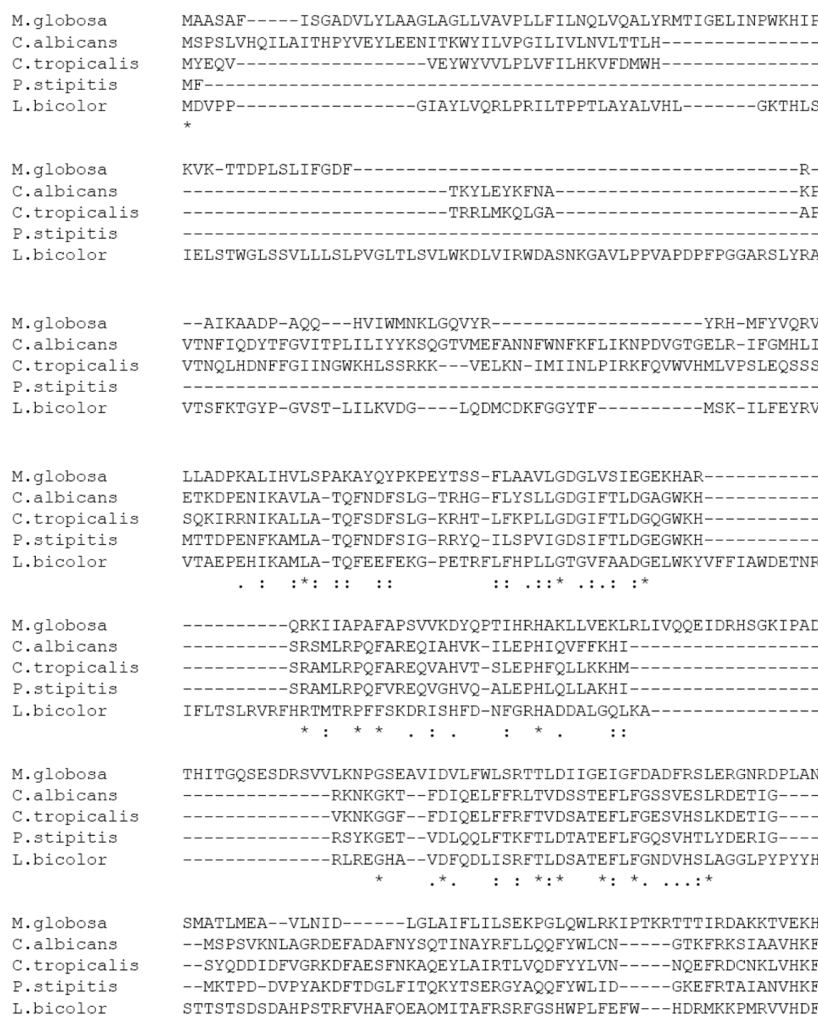

IELSTWGLSSVLLLSLPVGLTLSVLWKDLVIRWDASNKGAVLPPVAPDPFPGGARSLYRA

--AIKAADP-AQQ---HVIWMNKLGQVYR----------------YRH-MFYVQRV VTNF IQDYTFGVITPLILIYYKSQGTVMEFANNFWNFKFLIKNPDVGTGELR-IFGMHL VTNQLHDNFFGI INGWKHLSSRKK---VELKN- IMI INLPIRKFQVWVHMLVPSLEQSS VTSFKTGYP-GVST-IILKVDG---IQDMCDKFGGYTF---

LLADPKALIHVLSPAKAYQYPKPEYTSS-FLAAVLGDGLVSIEGEKHAR--

ETKDPENIKAVLA-TQFNDESLG-TRHG-FLYSLLGDGI FTLDGAGWKH --

MTTDPENFKAMLA-TQFNDFSIG-RRYQ-ILSPVIGDS IFTLDGEGWKH--

VIDEPEHIKAMLO-

RRI IAPAFAPSVVKDYQPTI IHRHAKLLVEKLRLIVQQEIDRHSGKTPAD

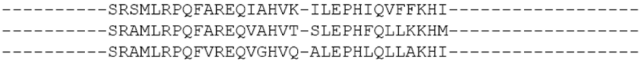

IFLTSLRVRFHRTMTRPF SKDDISHED-NEGRHADDALGQLKA -RKNKGKT--FDIQELFFRLIVDSSTE LFGSSVESLRDETIG-

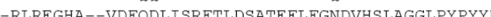
G

SMATLMEA--VLNID------LGLAIFLILSEKPGLQWLRKIPTKRTTTIRDAKKTVEKH -MSPSVKNLAGRDEFADAFNYSOT INAYRFLLQQFYWLCN-----GTKFRKS IAAVHK -SYQDDIDFVGRKDFAES FNKAQEYLAIRTLVQDFYYLVN-----NOEFRDCNKIVHK -MKTPD-DVPYAKDFTDGLFITQKYTSERGYAQQFYWLID-----GKEFRTAIANVHK STTSTSDSDAHPSTRFVHAFOEAOMITAFRSRFGSHWPLFEFW---HDRMKKPMRVVHDF

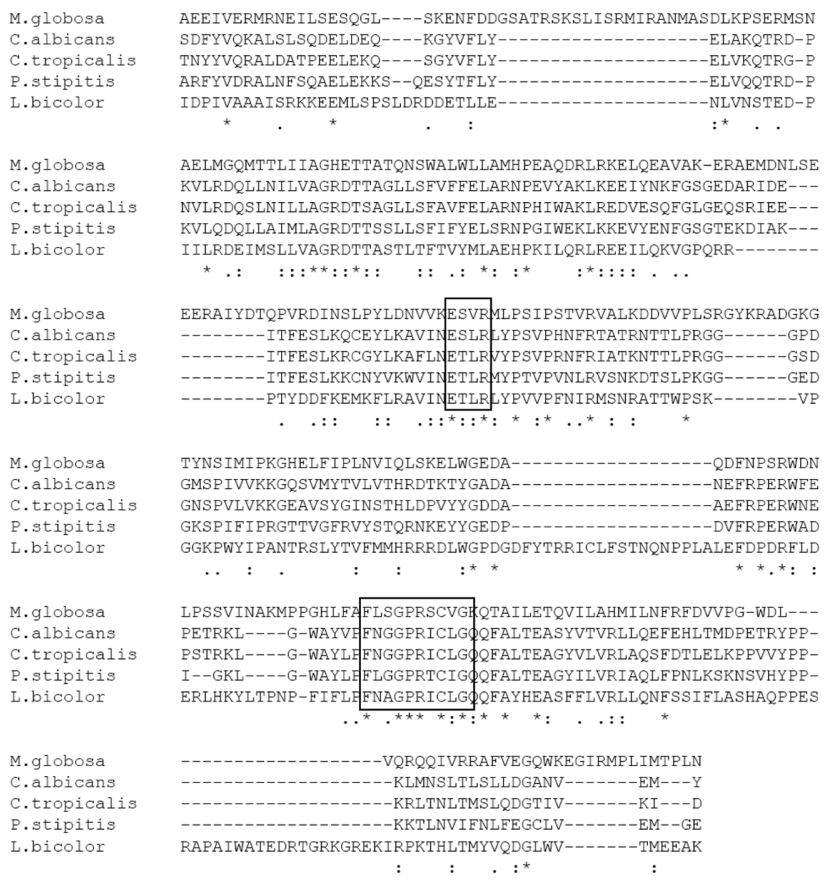

Fig. 2. Multiple sequence alignment of the Malassezia MGL3996 amino acid sequence with four other CYP52 proteins. The amino acid sequences were aligned using the software T-Coffee from the Swiss Institute of Bioinformatics (http://www.ch.embnet.drg/software/Tcoffee.html). M. globosa MGL3996 sequence was compared with Candida albicans CYP52A1, Candida tropicalis CYP52A8, Pichia stipitis CYP52A3 and Laccaria bicolor CYP52-1 amino acid sequences. Boxes indicate EXXR region in K-helix and conserved heme-binding motif. $\left(^{*}\right)$ indicate identical residues; (:) indicate semi-conserved residues; (.) designate conserved residues.

Laccaria bicolor CYP52-1 revealed a high sequence similarity with a score $78,78,84$ and $72 \%$, respectively (Fig. 2). The good sequence alignment of MGL3996 with other CYP52 suggests that they may have similar enzymatic specificities.

To confirm whether MGL3996 gene product shows a property of P450 enzymes, cloned MGL3996 gene was subcloned into the pPICZA $\alpha$ expression vector for expressing in $P$. pastoris yeast using restriction sites of $S f u \mathrm{I}$ and $X b a \mathrm{I}$ (Fig. 3). To facilitate expression and further purification of $\mathrm{P} 450$, six histidine residues were introduced just before the termination codon. The recombinant pPICZA $\alpha$ plasmid was successfully transformed into $P$. pastoris X-33 strain for high-level expression. After the continuous induction with methanol for $96 \mathrm{~h}$, cells were collected and membrane fractions were isolated. Isolated membrane fractions expressing MGL3996 protein had a typical $\mathrm{Fe}^{2+}-\mathrm{CO}$ versus $\mathrm{Fe}^{2+}$ difference spectrum which is characteristic for P450 enzymes (Fig. 4). The absorption maximum was at $448 \mathrm{~nm}$ and the expression level was about 2 nmol P450 per $\mathrm{m} l$ of membranes.

To verify the expression of MGL3996 protein in $P$. pastoris, SDS-PAGE and Western blot analysis were per- formed with cellular lysates after methanol induction for $96 \mathrm{~h}$. SDS-PAGE result showed that a protein band of apparent molecular weight of $69 \mathrm{kDa}$ was highly induced in the induced cell carrying pPICZ $\alpha$ A/MGL3996. No such band was detected in the control cells (Fig. 5A). Western blot with antibody against histidine tag clearly showed the band corresponding in size to the MGL3996 (Fig. 5B).

In this study, we report expression of $M$. globosa $\mathrm{P} 450$ in $P$. pastoris for the first time. Previously, we had been tried to express MGL3996 gene in E. coli system but could not detect P450 activity. Thus, we attempted to express MGL3996 gene in $P$. pastoris yeast expression system. The $P$. pastoris yeast system is heterologous protein expression systems to produce high levels of functional proteins ( $\mathrm{Li}$ et al., 2007; Daly and Hearn, 2005), which include membrane-bound proteins (Cregg et al., 1993; Cereghino and Cregg, 2006). The $P$. pastoris yeast system provides several advantages including stability of expression, easy-to-handling or a correct protein folding (Kolar et al., 2007). P. pastoris is considered as a better expression host for eukaryotic gene expression compared to $S$. cerevisiae.

The result that MGL3996 produced a clear CO-differ- 


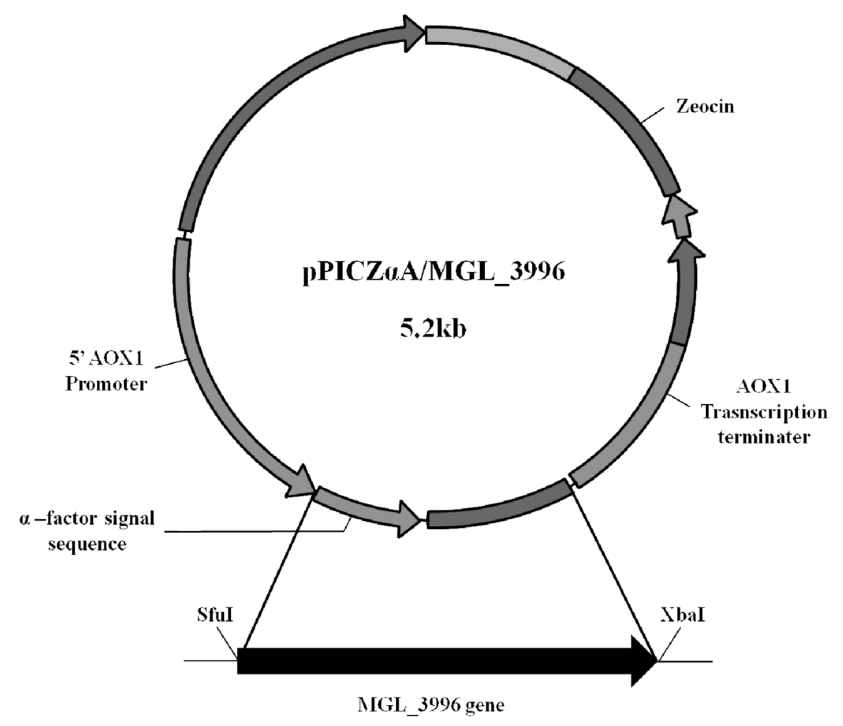

Fig. 3. Malassezia MGL3996 expression vector in P. pastoris. $5^{\prime}$ AOX1: alcohol oxidase 1 promoter region allows methanolinducible expression in $P$. pastoris, Zeocin: zeocin resistance gene derived from Streptoalloteichus hindustanus, AOX1 transcription terminator region: native transcription termination and polyadenylation signal from AOX1 gene permits mRNA processing, MGL3996: gene encoding M. globosa putative P450.

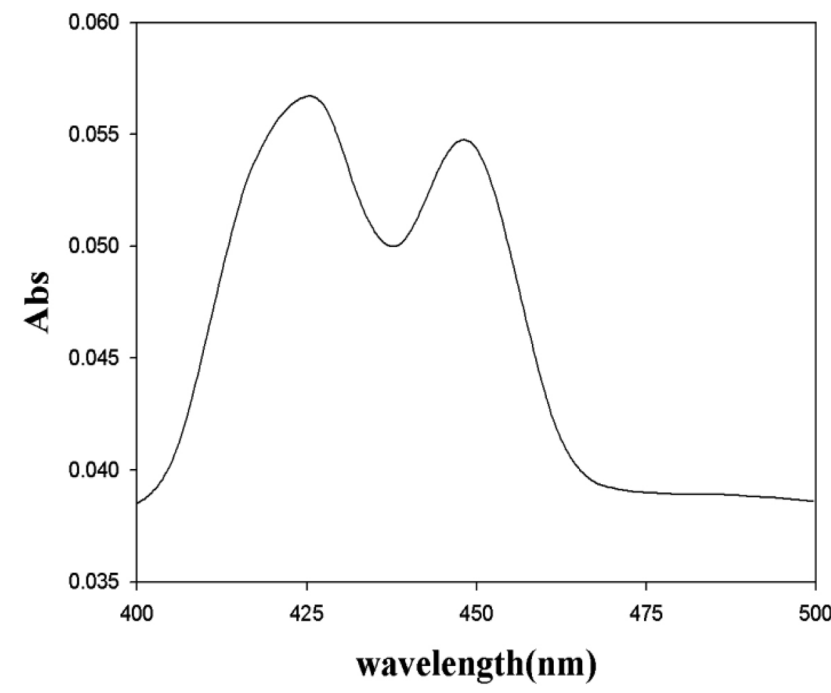

Fig. 4. $\mathrm{Fe}^{2+}-\mathrm{CO}$ versus $\mathrm{Fe}^{2+}$ difference spectra of Malassezia MGL3996 expressed in P. pastoris. P. pastoris cells transformed with pPICZ $\alpha \mathrm{A} / \mathrm{MGL} 3996$ were incubated in BMM media for $96 \mathrm{~h}$ after methanol induction. The membrane fractions were isolated and $\mathrm{Fe}^{2+}-\mathrm{CO}$ versus $\mathrm{Fe}^{2+}$ difference spectrum was measured. The calculated P450 level in the microsomal fraction is about $1.6 \mathrm{nmol}$ per $\mathrm{m} /$.

ence spectrum indicates that the MGL3996 may be a real P450 enzyme existed in $M$. globosa and $P$. pastoris system produces a correctly folded $\mathrm{P} 450$ protein. Although $P$. pas-

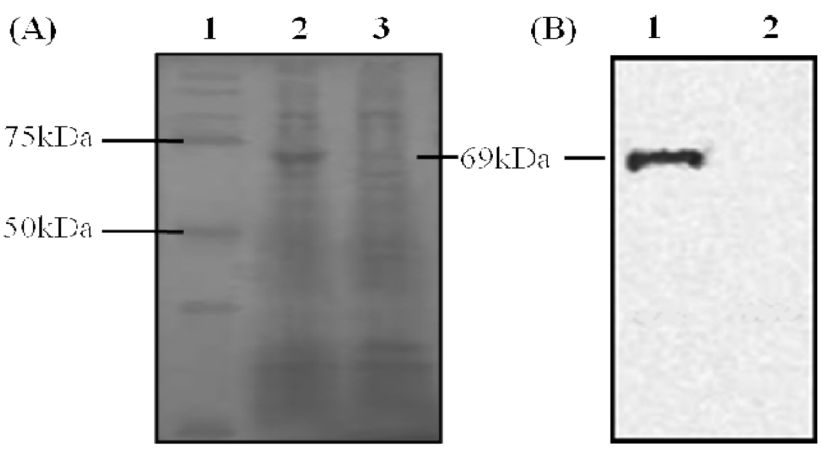

Fig. 5. SDS PAGE and Western blot analysis of expressed MGL3996. P. pastoris cells transformed with pPICZ $\alpha A / M G L 3996$ were incubated in BMM media for $96 \mathrm{~h}$ after methanol induction. Whole cell extracts were isolated, and then 10\% SDS-PAGE and Western blot analysis was performed. (A) SDS-PAGE. Lane 1, protein marker; lane 2, lysate of transformed cells; lane 3: lysate of control cells. Indicated $69 \mathrm{kDa}$ protein band represent the expressed MGL3996 protein. (B) Western blot analysis. Western blot was performed with anti-His-tag antibody. Lane 1, lysate of transformed cells; lane 2: lysate of control cells. Indicated $69 \mathrm{kDa}$ protein band represent the MGL3996 protein.

toris may contain endogenous $\mathrm{P} 450$ proteins, these must be expressed in very low levels because endogenous P450s were never detectable by CO-difference spectroscopy.

To date, only seven P450 enzymes have been expressed in P. pastoris, i.e., spiny dogfish shark CYP17 (Trant, 1996), plant CYP79D1 (Andersen et al., 2000), fungal PcCYP1f (Matsuzaki and Wariishi, 2005), human CYP2D6 (Dietrich et al., 2005), human CYP17 $\alpha$ (Kolar et al., 2007), Arabidopsis CYP78A9 (Ito and Meyerowitz, 2000) and CYP85A2 (Katsumata et al., 2008). For the first time, here we report successful expression of a Malassezia $\mathrm{P} 450$ in a $P$. pastoris expression system.

Altogether, our findings indicate that MGL3996, a probable P450 gene selected from M. globosa genome using sequence similarity analysis may be a functional P450 enzyme although information about enzymatic properties and chemical reactions still needs to be determined. Our establishment of $P$. pastoris expression system for Malassezia P450 gene will be valuable to understand the role of other P450 enzymes in Malassezia species.

\section{ACKNOWLEDGEMENT}

This study was supported by a grant of the Korea Healthcare Technology R\&D Project, Ministry of Health, Welfare and Family Affairs (A080065).

\section{REFERENCES}

Andersen, M.D., Busk, P.K., Svendsen, I. and Møller, B.L. (2000). Cytochromes P-450 from cassava (Manihot esculenta Crantz) 
catalyzing the first steps in the biosynthesis of the cyanogenic glucosides linamarin and lotaustralin. Cloning, functional expression in Pichia pastoris, and substrate specificity of the isolated recombinant enzymes. J. Biol. Chem., 275, 1966-1975.

Cafarchia, C. and Otranto, D. (2008). The pathogenesis of Malassezia yeasts. Parassitologia., 50, 65-67.

Cereghino, J.L. and Cregg, J.M. (2006). Heterologous protein expression in the methylotrophic yeast Pichia pastoris. FEMS Microbiol. Rev., 24, 45-66.

Cregg, J.M., Vedvick, T.S. and Raschke, W.C. (1993). Recent advances in the expression of foreign genes in Pichia pastoris. Bio/Technology, 11, 905-910.

Daly, R. and Hearn, M.T. (2005). Expression of heterologous proteins in Pichia pastoris: a useful experimental tool in protein engineering and production. J. Mol. Recognit., 18,119-138.

Dietrich, M., Grundmann, L., Kurr, K., Valinotto, L., Saussele, T., Schmid, R.D. and Lange, S. (2005). Recombinant production of human microsomal cytochrome P450 2D6 in the methylotrophic yeast Pichia pastoris. Chembiochem., 5, 2014-2022.

Faergemann, J. (1997). Pityrosporum yeasts-what's new? Mycoses, 40, 29-32.

Gemmer, C.M., DeAngelis, Y.M., Theelen, B., Boekhout, T. and Dawson, T.L. Jr. (2002). Fast, noninvasive method for molecular detection and differentiation of Malassezia yeast species on human skin and application of the method to dandruff microbiology. J. Clin. Microbiol., 40, 3350-3357.

Georgopapadakou, N.H. and Walsh, T.J. (1996). Antifungal agents: chemotherapeutic targets and immunologic strategies. Antimicrob. Agents Chemother., 40, 279-291.

Guého, E., Midgley, G. and Guillot, J. (1996). The genus Malasse$z i a$ with description of four new species. Antonie Van Leeuwenhoek., 69, 337- 355 .

Guillot, J., Hadina, S. and Guého, E. (2008). The genus Malassezia: old facts and new concepts. Parassitologia., 50, 77-79.

Ito, T. and Meyerowitz, E.M. (2000). Overexpression of a gene encoding a cytochrome P450, CYP78A9, induces large and seedless fruit in arabidopsis. Plant Cell, 12, 1541-1550.

Katsumata, T., Hasegawa, A., Fujiwara, T., Komatsu, T., Notomi, M., Abe, H., Natsume, M. and Kawaide, H. (2008). Arabidopsis CYP85A2 catalyzes lactonization reactions in the biosynthesis of 2-deoxy-7-oxalactone brassinosteroids. Biosci. Biotechnol. Biochem., 72, 2110-2117.

Kolar, N.W., Swart, A.C., Mason, J.I. and Swart, P. (2007). Functional expression and characterisation of human cytochrome P45017á in Pichia pastoris. J. Biotechnol., 129, 635-644.

Koltin, Y. and Hitchcock, C.A. (1997). Progress in the search for new triazole antifungal agents. Curr. Opin. Chem. Biol., 1, 176182.

Li, P., Anumanthan, A., Gao, X.G., Ilangovan, K., Suzara, V.V., Düzgüneș, N. and Renugopalakrishnan, V. (2007). Expression of recombinant proteins in Pichia pastoris. Appl. Biochem. Biotechnol., 142, 105-124.
Matsuzaki, F. and Wariishi, H. (2005). Molecular characterization of cytochrome P450 catalyzing hydroxylation of benzoates from the white-rot fungus Phanerochaete chrysosporium. Biochem. Biophys. Res. Commun., 334, 1184-1190.

Mayser, P., Haze, P., Papavassilis, C., Pickel, M., Gruender, K. and Guého, E. (1997). Differentiation of Malassezia species: selectivity of cremophor EL, castor oil and ricinoleic acid for M. furfur. Br. J. Dermatol., 137, 208-213.

Morishita, N., Sei, Y. and Sugita, T. (2006). Molecular analysis of Malassezia microflora from patients with pityriasis versicolor. Mycopathologia., 161,61-65.

Nelson, D.R., Koymans, L., Kamataki, T., Stegeman, J.J., Feyereisen, R., Waxman, D.J., Waterman, M.R., Gotoh, O., Coon, M.J., Estabrook, R.W., Gunsalus, I.C. and Nebert, D.W. (1996). P450 superfamily: update on new sequences, gene mapping, accession numbers and nomenclature. Pharmacogenetics, 6, 142.

Ohkuma, M., Muraoka, S., Tanimoto, T., Fujii, M., Ohta, A. and Takagi, M. (1995). CYP52 (cytochrome P450alk) multigene family in Candida maltosa: identification and characterization of eight members. DNA Cell Biol., 14, 163-173.

Omura, T. and Sato, R. (1964). The carbon-monoxide binding pigment of liver microsomes. J. Biol. Chem., 239, 2370-2378.

Riciputo, R.M., Oliveri, S., Micali, G. and Sapuppo, A. (1996). Phospholipase activity in Malassezia furfur pathogenic strains. Mycoses, 39, 233-235.

Scheller, U., Zimmer, T., Kärgel, E. and Schunck, W.H. (1996). Characterization of the n-alkane and fatty acid hydroxylating cytochrome P450 forms 52A3 and 52A4. Arch. Biochem. Biophys., 328, 245-254.

Sheehan, D.J., Hitchcock, C.A. and Sibley, C.M. (1999). Current and emerging azole antifungal agents. Clin. Microbiol. Rev., 12, 40-79.

Sugita, T., Tajima, M., Ito, T., Saito, M., Tsuboi, R. and Nishikwa, A. (2005). Antifungal activities of tacrolimus and azole agents against the eleven currently accepted Malassezia species. $J$. Clin. Microbiol., 43, 2824-2829.

Trant, J.M. (1996). Functional expression of recombinant spiny dogfish shark (Squalus acanthias) cytochrome P450c17 (17 alpha-hydroxylase/C17,20-lyase) in yeast (Pichia pastoris). Arch. Biochem. Biophys., 326, 8-14.

$\mathrm{Xu}$, J., Saunders, C.W., Hu, P., Grant, R.A., Boekhout, T., Kuramae, E.E., Kronstad, J.W., Deangelis, Y.M., Reeder, N.L., Johnstone, K.R., Leland, M., Fieno, A.M., Begley, W.M., Sun, Y., Lacey, M.P., Chaudhary, T., Keough, T., Chu, L., Sears, R., Yuan, B. and Dawson, T.L. Jr. (2007). Dandruff-associated Malassezia genomes reveal convergent and divergent virulence traits shared with plant and human fungal pathogens. Proc. Natl. Acad. Sci. USA, 104, 18730-18735.

Zisova, L.G. (2009). Malassezia species and seborrheic dermatitis. Folia Med., 51, 23-33. 